\title{
Highly Efficient and Stable Pure Blue Nondoped Organic Light-Emitting Diodes at High Luminance Based on Phenanthroimidazole-Pyrene Derivative Enabled by Triplei- Triplet Annihilation
}

Tong Shan ${ }^{\mathrm{a}}, \dagger$ Zhao Gao ${ }^{\mathrm{a}} \dagger$ Xiangyang Tanga, Xin Hea, Yu Gao ${ }^{a}$, Jinyu Lia, Xiaoyi Suna, Yulong Liua, Haichao Liua ${ }^{a}$ Bing Yanga, Ping Lua,*, and Yuguang Mab

\begin{abstract}
To promote the application of organic light emitting diodes (OLEDs) in various areas, achieving high performance blue OLEDs with outstanding efficiencies at high luminance is still desired. Herein, we focus on realizing stable and highly efficient pure blue OLED capable of harvesting triplets via triplet-triplet annihilation (TTA). Three fused polycyclic aromatic substituents, naphthalene, pyrene and anthracene, are selected to construct phenanthroimidazole-functionalized molecules (1-3), among which pyrene and anthracene comprised ones display TTA characteristics in electroluminescence devices. High photoluminescence quantum efficiency of $57 \%$ is found in the neat film of emitter 2 from judicious molecular design. The nondoped OLED of $\mathbf{2}$ exhibits pure blue emission with CIE coordinates of $(0.15,0.14)$ and demonstrates a maximum external quantum efficiency (EQE) of $5.11 \%$, stable EQE over $5 \%$ at luminance of $300 \sim 3000 \mathrm{~cd} \mathrm{~m}^{-2}$, EQE of $4.76 \%$ at an ultrabright luminance of $10000 \mathrm{~cd} \mathrm{~m}^{-2}$ and a maximum luminance of $54300 \mathrm{~cd} \mathrm{~m}^{-2}$. Such great device performance are responsible for the appreciable TTA contribution substantially.

Keywords: Triplet-triplet annihilation; Pure blue; Pyrene; High luminance; OLEDs
\end{abstract}

\section{Introduction}

Ever since the dawn of organic light-emitting diodes (OLEDs) reported by Tang and coworkers [1], there has been a sustained pursuit to develop high efficient, stable devices for applications capable of generating light of all visible colors. Lagging far behind green and red 
OLEDs which are reliable enough for practical application, high performance blue OLEDs are still on our wish list. Green and red electrophosphorescent devices have been used in commercial flat-panel displays with up to $100 \%$ internal quantum efficiencies (IQE) [2]. However, the majority actual practical blue devices still rely on electrofluorescence based on anthracene derivatives [3]. Similar to electrophosphorescent devices, for blue ones, OLEDs of thermally activated delayed fluorescence (TADF) luminophors with electrical-to-optical conversion efficiencies reaching unity also suffer from sharp efficiency roll-off at luminance of hundreds of candela per square meter $\left(\mathrm{cd} \mathrm{m}^{-2}\right)$ [4-6] being in principle necessary for displays application, because the longevity triplet excitons promising to generate radiative decay would quench with each other at high current density. As for general-purpose lightings industry, white organic light-emitting diodes show great promise to be made as a "surface source" providing lighting that is free of glare, whereas rarely WOLEDs could sustain satisfactory efficiency at high brightness of at least $1000 \mathrm{~cd} \mathrm{~m}^{-2}$ [7-8], which should be ascribed to the poor performance of blue component in WOLEDs. All above can be summarized to just one: only energetically exploit high performance blue OLEDs with outstanding efficiencies at high luminance can promote the application of OLEDs in various areas.

Considering that the internal quantum efficiency (IQE) in exemplary fluorescent OLEDs is generally limited to $25 \%$ according to spin statistics [9], concurrently harvesting singlet and triplet excitons in electroluminescence (EL) process is essential to actualize high efficiency OLEDs. Another approach to light generation in OLEDs, triplet-triplet annihilation (TTA), is a bimolecular process that two created triplet excitons collisions give origin to an emissive excited singlet exciton via several mechanism [10-11], which is referred to triplet fusion (TF) as well. The intensity of TTA-related emission intensely varies with the current density, deriving from the different collision probability of excitons. As a result, the quadratic and linear dependences of TTA-related emission on current density in principle could be predicted at low and high current density regimes, respectively [12-15]. As proved by Monkmanand coworkers, TTA process could contribute an extra singlet exciton ratio of approximately $15 \% \sim 37.5 \%$ with subsequently radiative transition [15], compared to the exemplary fluorescent OLEDs, consequently overing an IQE up to $62.5 \%(25 \%+37.5 \%)$ in EL device by circumspect molecular design [15-16]. Fortunately, high current density is propitious to generate extra emissive portion through added TF processes and in consequence achieving 
high luminance with high efficiency simultaneously is more feasible by employing TTA [15,17-19]. The different utilization pattern of triplets make it conceivable to get great performance in nondoped TTA based OLEDs [20-22], which is simpler for device fabrication than phosphorescent and TADF ones requiring dispersing emitters into matrix [23-24]. In addition, it is limited in extensive industry production for the high cost of phosphorescent materials composed of rare metal complexes [25]. In light of all these advantages, facile and cost-effective approaches to fabricate TTA based devices show promise to elevate the competitiveness of OLEDs for practical applications.

With the investigations of TTA processes in blue OLEDs deepening, researchers were mainly focused on fused polycyclic aromatic cores such as anthracene (An) [26-29] and pyrene (Py) $[19,22,29-31]$, whose double energy of triplet is larger than singlet one, i.e., $2 E_{T 1}>E_{S 1}$, making them capable of up-converting triplets into singlets through TTA [32]. We have confirmed in our previous studies that phenanthroimidazole (PI) group is an excellent skeleton to construct saturate blue emitter for its high photoluminescence quantum efficiency (PLQY) and balanced ambipolar carrier transport properties capable of depress the efficiency roll-off [33-37].PI based derivatives exhibited some intriguing properties that the aryl substituents linked at position of imidazole C2 can extend the $\pi$-conjugation, judiciously adjust the electronic properties, provide effective hindrance to interchromophore packing and improve PLQY.

In the present work, two novel well-defined PI derivatives (2 and 3) with Py and An introduced to $\mathrm{C} 2$ of imidazole respectively were developed. The investigation of different molecule architectures employing unique optical and electrical properties of PI derivatives and their strong effects on the characteristics of blue OLEDs were reported. In contrast with our reported one (1) composed of PI and naphthalene [34], 2 and 3 displayed distinctly roll-up efficiency curves at low current density and nearly invariable efficiency at luminance of 200 10000 $\mathrm{cd} \mathrm{m}^{-2}$ in their nondoped OLEDs, which signified appreciable TTA contribution in EL processes substantially. Especially, 2-based device demonstrated pure blue EL emission with Commission International de L'Eclairage (CIE) coordinates of $(0.154,0.141)$, external quantum efficiency (EQE) of $4.57 \% \sim 5.11 \%$ at luminance of $100 \sim 1000 \mathrm{~cd} \mathrm{~m}^{-2}, 4.76 \%$ at luminance of $10000 \mathrm{~cd} \mathrm{~m}^{-2}$ and maximum luminance of $54300 \mathrm{~cd} \mathrm{~m}^{-2}$.

\section{Experimental section}

\subsection{General information}


All the reagents and solvents used for the synthesis were purchased from Aldrich and Acros companies and used without further purification. The 1H NMR spectra were recorded on AVANCE 500 spectrometers at $500 \mathrm{MHz}, 298 \mathrm{~K}$, utilizing deuterated dimethyl sulfoxide (DMSO- $d_{6}$ ) as solvents and tetramethylsilane (TMS) as a standard. The element contents of the compounds were characterized by a Flash EA 1112, CHNS-O elemental analysis instrument. The MALDI-TOF mass spectra were recorded by an AXIMA-CFRTM plus instrument. Thermal gravimetric analysis (TGA) was undertaken on a PerkinElmer thermal analysis system with a heating rate of $10{ }^{\circ} \mathrm{C} \mathrm{min}^{-1}$. Differential scanning calorimetry (DSC) analysis was carried out through a NETZSCH (DSC-204) instrument from $20^{\circ} \mathrm{C}$ to $360^{\circ} \mathrm{C}$ at $10{ }^{\circ} \mathrm{C} \mathrm{min}^{-1}$ while flushing with nitrogen. UV-vis absorption spectra were recorded on a UV-3100 spectrophotometer. Fluorescence measurements were carried out with a RF-5301PC. The room-temperature lifetimes were measured on an Edinburgh FLS-980 with an EPL-375 optical laser. PL efficiencies in solvents were measured with a UV-3100 and a RF-5301PC, relative to quinine sulfate (54.6\%). PL efficiencies in film were measured on a Gliden Fluorescence System. The time-resolved PL spectra were measured at $77 \mathrm{~K}$ in THF using an Edingburg LP-920. Cyclic voltammetry (CV) was performed with a BAS 100W Bioanalytical Systems, using a glass carbon disk $(\Phi=3 \mathrm{~mm})$ as the working electrode, a platinum wire as the auxiliary electrode with a porous ceramic wick, $\mathrm{Ag} / \mathrm{Ag}^{+}$as the reference electrode, standardized for the redox couple ferricinium/ferrocene $\left(\mathrm{Fc}^{+} / \mathrm{Fc}\right)$ with formal potential of is $4.8 \mathrm{eV}$ below vacuum. In each case, the anodic scan was performed in dichloromethane (DCM), while the cathodic scan was conducted in dry degassed DMF. All solutions were purged with nitrogen stream for 10 min before measurements. The procedure was performed at room temperature and a nitrogen atmosphere was maintained over the solution during measurements. All potentials relative to $\mathrm{Ag} / \mathrm{Ag}^{+}$electrode obtained from $\mathrm{CV}$ measurement were eventually referenced against $\mathrm{Fc}^{+} / \mathrm{Fc}$ to calculate $\mathrm{HOMO} / \mathrm{LUMO}$ levels. As a result, the $\mathrm{Ag} / \mathrm{Ag}^{+}$electrode is just a pseudo reference. The HOMO/LUMO energy levels of the materials versus the vacuum levels were estimated from the estimated onset potential of oxidation/reduction and were calculated according to the following formula:

\subsection{Device fabrications and measurements}

ITO-coated glass with a sheet resistance of $20 \Omega$ square $^{-1}$ was used as the substrate. Before device fabrication, the ITO glass substrates were cleaned by deionized water, 
isopropyl alcohol, acetone and toluene, dried in an oven at $120^{\circ} \mathrm{C}$, treated with UV-zone for $30 \mathrm{~min}$, and finally transferred to a vacuum deposition system with the base pressure lower than $5 \times 10^{-4} \mathrm{~Pa}$ for organic and metal deposition. The devices were fabricated by evaporating organic layers with an evaporation rate of $0.5-1 \AA^{-1}$. The cathode was completed through thermal deposition of LiF at a deposition rate of $0.1 \AA \mathrm{s}^{-1}$, and then capped with $\mathrm{Al}$ through thermal deposition at a deposition rate of 3-5 $\AA \mathrm{s}^{-1}$. EL characteristics of the devices were measured with a computer controlled Keithley 2400 source meter and Konica Minolta CS200 color and luminance meter under ambient condition. EL spectra and CIE color coordinates (1931) were measured with a Spectrascan PR-650 photometer.

\subsection{Synthesis and characterization}

\section{2-(naphthalen-1-yl)-1-phenyl-1H-phenanthro[9,10-d]imidazole (1):}

A mixture of 1-naphthaldehyde $(0.44 \mathrm{~g}, 2.8 \mathrm{mmol})$, phenanthrene-9,10-dione $(0.63 \mathrm{~g}, 2.9$ $\mathrm{mmol})$, aniline $(1.19 \mathrm{~g}, 12.8 \mathrm{mmol})$, ammonium acetate $(1.19 \mathrm{~g}, 10.2 \mathrm{mmol})$, and acetic acid $(30 \mathrm{~mL})$ were refluxed under nitrogen in an oil bath. After $2 \mathrm{~h}$, the mixture was cooled and filtered. The resulting mixture was extracted with chloroform followed by purification by column chromatography on silica gel with petroleum ether/dichloromethane (1:3) as the eluent and further purified by sublimation under vacuum to offer a colorless solid in $60 \%$ yield (0.75 g). ${ }^{1} \mathrm{H}$ NMR (500 MHz, DMSO-D 6 , $): 8.98(\mathrm{~d}, J=8.3 \mathrm{~Hz}, 1 \mathrm{H}), 8.93(\mathrm{~d}, J=8.3 \mathrm{~Hz}, 1 \mathrm{H})$, $8.66(\mathrm{dd}, J=7.9,1.2 \mathrm{~Hz}, 1 \mathrm{H}), 7.98(\mathrm{t}, J=8.4 \mathrm{~Hz}, 2 \mathrm{H}), 7.91(\mathrm{~d}, J=8.2 \mathrm{~Hz}, 1 \mathrm{H}), 7.79(\mathrm{t}, J=7.4$ $\mathrm{Hz}, 1 \mathrm{H}$ ), 7.71 (ddd, $J=12.5,7.7,3.8 \mathrm{~Hz}, 2 \mathrm{H}), 7.64-7.57(\mathrm{~m}, 3 \mathrm{H}), 7.57-7.47(\mathrm{~m}, 3 \mathrm{H}), 7.47$ - $7.40(\mathrm{~m}, 3 \mathrm{H}), 7.37$ (t, $J=7.7 \mathrm{~Hz}, 1 \mathrm{H}), 7.12$ (d, $J=7.6 \mathrm{~Hz}, 1 \mathrm{H})$. MALDI-TOF (m/z): Found: $\left[M^{+} H\right]^{+}$421.3; $\mathrm{C}_{31} \mathrm{H}_{20} \mathrm{~N}_{2}$ requires $\left[\mathrm{M}^{+} \mathrm{H}\right]^{+}$421.50. Elemental analyses: Found: $\mathrm{C}, 88.68 ; \mathrm{H}$, 4.69; $\mathrm{N} 6.63 \% ; \mathrm{C}_{31} \mathrm{H}_{20} \mathrm{~N}_{2}$ requires: C, 88.54; $\mathrm{H}, 4.79 ; \mathrm{N} 6.66 \%$.

\section{2-(4,6-dihydropyren-1-yl)-1-phenyl-1H-phenanthro[9,10-d]imidazole (2):}

A mixture of pyrene-1-carbaldehyde $(2.00 \mathrm{~g}, 8.6 \mathrm{mmol})$, phenanthrene-9,10-dione (2.06 g, $9.9 \mathrm{mmol})$, aniline $(3.98 \mathrm{~g}, 42.9 \mathrm{mmol})$, ammonium acetate $(2.59 \mathrm{~g}, 33.6 \mathrm{mmol})$, and acetic acid $(60 \mathrm{~mL})$ were refluxed under nitrogen in an oil bath. After $2 \mathrm{~h}$, the mixture was cooled and filtered. The resulting mixture was extracted with chloroform followed by purification by column chromatography on silica gel with petroleum ether/dichloromethane (1:4) as the eluent and further purified by sublimation under vacuum to offer a yellowish solid in $75 \%$ yield. ${ }^{1} \mathrm{H}$ NMR (500 MHz, DMSO-D 6 , ס): 9.03 (d, J = $\left.8.83 \mathrm{~Hz}, 1 \mathrm{H}\right), 8.98(\mathrm{~d}, \mathrm{~J}=8.28 \mathrm{~Hz}, 1 \mathrm{H}$ ), 
$8.73(\mathrm{~d}, \mathrm{~J}=7.77 \mathrm{~Hz}, 1 \mathrm{H}), 8.39-8.35(\mathrm{~m}, 2 \mathrm{H}), 8.29-8.26(\mathrm{~m}, 2 \mathrm{H}), 8.20(\mathrm{~d}, \mathrm{~J}=6.55 \mathrm{~Hz}, 4 \mathrm{H})$, $8.16(\mathrm{t}, \mathrm{J}=7.59 \mathrm{~Hz}, 7.67 \mathrm{~Hz}, 1 \mathrm{H}), 7.81(\mathrm{t}, \mathrm{J}=7.22 \mathrm{~Hz}, 8.00 \mathrm{~Hz}, 1 \mathrm{H}), 7.76(\mathrm{t}, \mathrm{J}=7.06 \mathrm{~Hz}, 6.95$ $\mathrm{Hz}, 1 \mathrm{H}), 7.69(\mathrm{~d}, \mathrm{~J}=6.55 \mathrm{~Hz}, 2 \mathrm{H}), 7.64(\mathrm{t}, \mathrm{J}=7.18 \mathrm{~Hz}, 8.24 \mathrm{~Hz}, 1 \mathrm{H}), 7.41-7.39(\mathrm{~m}, 4 \mathrm{H}), 7.19$ $(\mathrm{d}, \mathrm{J}=7.38 \mathrm{~Hz}, 1 \mathrm{H})$. MALDI-TOF $(\mathrm{m} / \mathrm{z})$ : Found: $\left[\mathrm{M}^{+} \mathrm{H}\right]^{+} 495.60 ; \mathrm{C}_{37} \mathrm{H}_{22} \mathrm{~N}_{2}$ requires $\left[\mathrm{M}^{+} \mathrm{H}\right]^{+}$ 495.58. Elemental analyses: Found: $\mathrm{C}, 88.99 ; \mathrm{H}, 4.42 ; \mathrm{N} 6.59 \% ; \mathrm{C}_{37} \mathrm{H}_{22} \mathrm{~N}_{2}$ requires: $\mathrm{C}, 89.85$; $H, 4.48 ; \mathrm{N} 5.66 \%$.

\section{2-(anthracen-9-yl)-1-phenyl-1H-phenanthro[9,10-d]imidazole (3):}

A mixture of 1-naphthaldehyde (1.02 g, $4.9 \mathrm{mmol})$, phenanthrene-9,10-dione (1.16 g, 5.9 $\mathrm{mmol})$, aniline $(2.26 \mathrm{~g}, 24.3 \mathrm{mmol})$, ammonium acetate $(1.45 \mathrm{~g}, 18.8 \mathrm{mmol})$, and acetic acid $(35 \mathrm{~mL})$ were refluxed under nitrogen in an oil bath. After $2 \mathrm{~h}$, the mixture was cooled and filtered. The resulting mixture was extracted with chloroform followed by purification by column chromatography on silica gel with petroleum ether/dichloromethane (1:1) as the eluent and further purified by sublimation under vacuum to offer a yellow solid in $50 \%$ yield. ${ }^{1} \mathrm{H}$ NMR (500 MHz, DMSO-D $\left.6, \delta\right): 9.03(\mathrm{~d}, \mathrm{~J}=8.31 \mathrm{~Hz}, 1 \mathrm{H}), 8.98(\mathrm{~d}, \mathrm{~J}=8.15 \mathrm{~Hz}, 1 \mathrm{H}), 8.74$ (s, 1H), $8.67(\mathrm{~d}, \mathrm{~J}=7.95 \mathrm{~Hz}, 1 \mathrm{H}), 8.13(\mathrm{~d}, \mathrm{~J}=8.98 \mathrm{~Hz}, 2 \mathrm{H}), 7.80(\mathrm{t}, \mathrm{J}=6.88 \mathrm{~Hz}, 6.96 \mathrm{~Hz}, 1 \mathrm{H})$, 7.75-7.72 (m, 3H), $7.64(\mathrm{t}, \mathrm{J}=8.25 \mathrm{~Hz}, 7.16 \mathrm{~Hz}, 1 \mathrm{H}), 7.55-7.50(\mathrm{~m}, 4 \mathrm{H}), 7.46(\mathrm{~d}, \mathrm{~J}=7.03 \mathrm{~Hz}$, 2H), 7.40 (t, J = 7.27 Hz, 7.13 Hz, 1H), 7.29-7.22 (m, 3H), 7.12 (d, J = 7.45 Hz, 1H). MALDITOF $(\mathrm{m} / \mathrm{z})$ : Found: $\left[\mathrm{M}^{+} \mathrm{H}\right]^{+}$471.40; $\mathrm{C}_{35} \mathrm{H}_{22} \mathrm{~N}_{2}$ requires $\left[\mathrm{M}^{+} \mathrm{H}\right]^{+}$471.56. Elemental analyses: Found: $\mathrm{C}, 89.49 ; \mathrm{H}, 4.65 ; \mathrm{N} 5.83 \% ; \mathrm{C}_{35} \mathrm{H}_{22} \mathrm{~N}_{2}$ requires: $\mathrm{C}, 89.33 ; \mathrm{H}, 4.71 ; \mathrm{N} 5.95 \%$.

\section{Results and discussion}

\subsection{Synthetic procedures}

All these compounds used for this study were readily synthesized by the DebusRadziszewski reaction in good yields according to our reported procedure. The synthetic route was shown in Scheme 1. The detailed procedures for the syntheses of the final products were described below. The molecular structure was characterized by ${ }^{1} \mathrm{H}$ NMR, mass spectrometry, elemental analysis, and corresponded well with their expected structure. The corresponding ${ }^{1} \mathrm{H}$ NMR spectra are shown in the supporting information (Figure S1). 


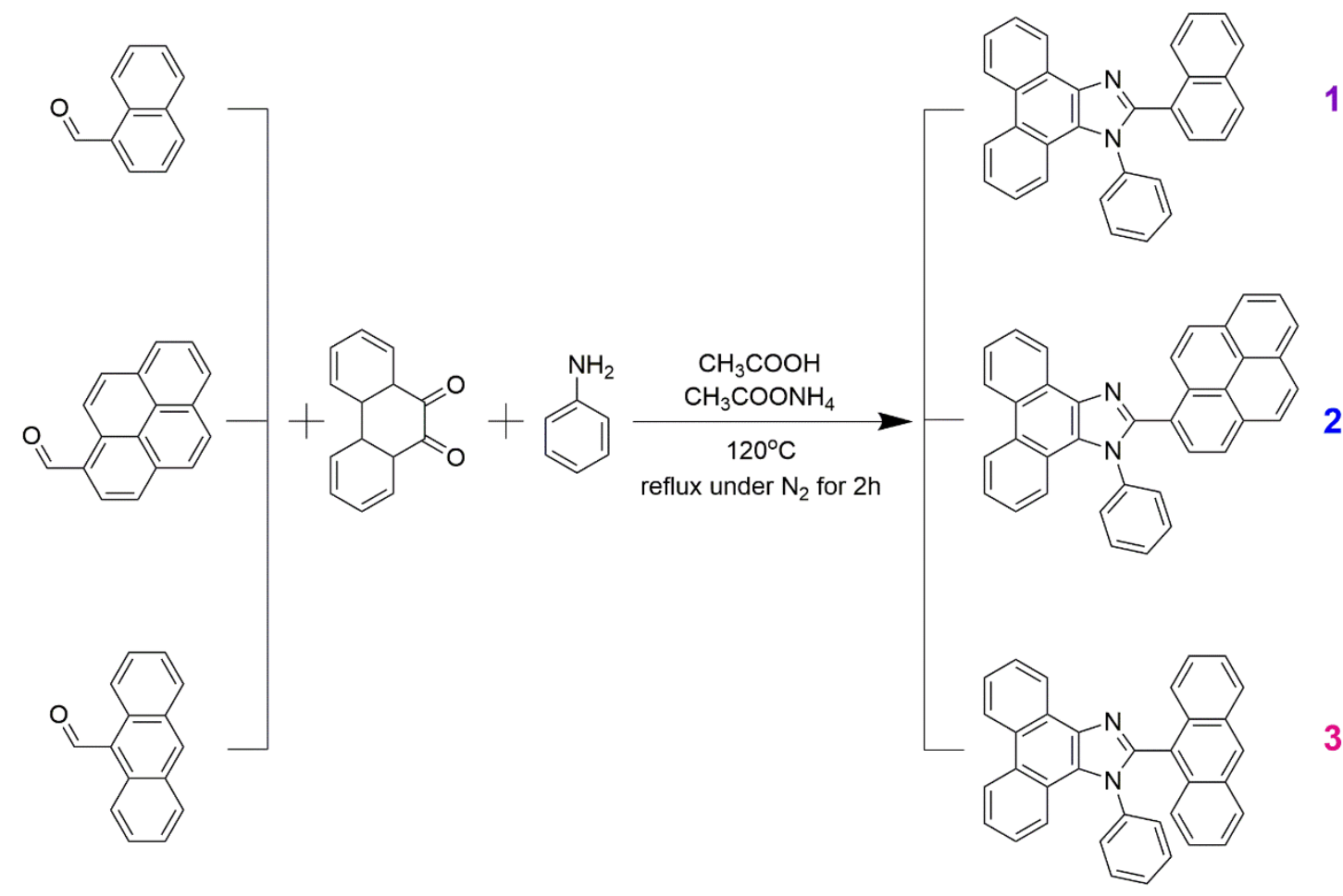

Scheme 1. Molecular structures and synthetic procedure of PI derivatives 1-3.

\subsection{Crystal structural}

The molecular structures of 1-3 were further confirmed by single-crystal X-ray analysis. The crystallographic data are listed in Table S1, while the molecular structure and crystal packing diagrams are shown in Figure 1. In these crystals, these PI derivatives adopt a highly twisted conformation with large dihedral angle, which could effectively suppress the formation of coplanar aggregation. The dihedral angles between aryl and PI of 1 and 2 were $83^{\circ}$ and $76^{\circ}$, respectively, whereas two configurations were found in crystal $\mathbf{3}$ with nearly vertical formation $\left(87^{\circ}\right.$ and $\left.93^{\circ}\right)$. Intermolecular $\pi-\pi$ interactions were merely found in crystal $\mathbf{1}$ and $\mathbf{3}$, ensuring sufficient PLQY in solid state. Unfortunately, as shown in Figure 1b, Py units in the crystal 2 displayed a 4-point $\Pi-\pi$ stacking with overlap of a benzene ring size showing interplanar separation of approximate $3.51 \AA$ (Figure S2). The strong $\pi-\pi$ stacking frequently reported in Py derivatives [38] generally follows decreased PLQY in solid state. 

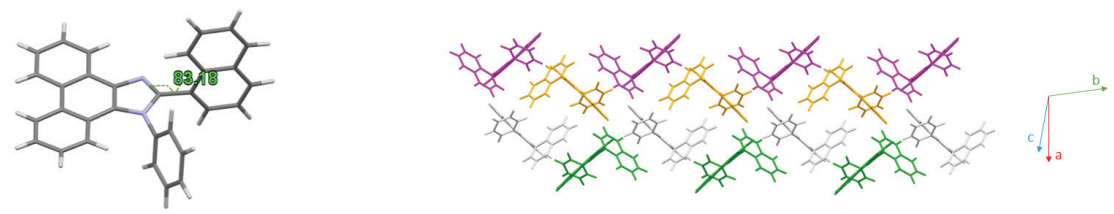

b
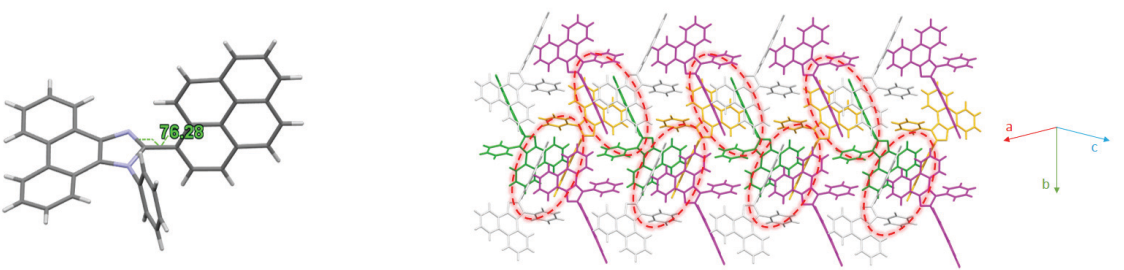

c]
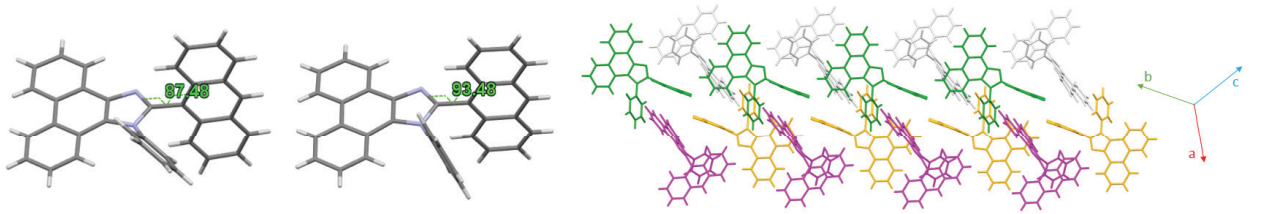

Figure 1. The molecular structures and packing diagrams of (a) 1, (b) 2, and (c) 3.

\subsection{Thermal properties}

The thermal properties of these PI derivatives were investigated using thermogravimetric analysis (TGA) and differential scanning calorimetry (DSC) under a nitrogen atmosphere, and their thermal data are summarized in Table 1. The rigid bulky substituents of naphthalene, An and Py could enlarge the molecular size, which would provide better thermal stability. Large amount of joule heat generated from high current density in operating EL devices further requires the materials with thermal stability at high temperature. High glass transition temperature $\left(T_{\mathrm{g}}\right)$ of $99{ }^{\circ} \mathrm{C}$ and $140{ }^{\circ} \mathrm{C}$ were observed for 1 and 3 . Meanwhile, the melting temperature $\left(T_{\mathrm{m}}\right)$ of 1 and 3 were approximately $300{ }^{\circ} \mathrm{C}$. There was no glass transition or melting processes observed from $20^{\circ} \mathrm{C}$ to $360{ }^{\circ} \mathrm{C}$ for 2 , which was adequate for application in OLEDs. It was demonstrated that attaching much bigger substituents could greatly enhanced the thermal stability. 1-3 also exhibited high thermal decomposition temperature $\left(T_{\mathrm{d}}\right)$ with $371^{\circ} \mathrm{C}, 423^{\circ} \mathrm{C}$ and $386^{\circ} \mathrm{C}$, respectively. The high $T_{\mathrm{d}}$ values of the compounds were ascribed to the aromatic rings possessing a high resistance to thermolysis. Such high $T_{\mathrm{g}}, T_{\mathrm{d}}$ value and glass state implies that they could form morphologically stable films upon thermal evaporation, which was highly important to improve the performance of EL devices.

\subsection{Photophysical properties}

Uv-vis absorption (ABS) and PL spectra of these two molecules are measured to explore their ground and excited states properties. The absorption and PL spectra were measured in 
tetrahydrofuran (THF) dilute solution and thin films on quartz substrates. As displayed in Figure 2a, all of them exhibited absorption around $307 \mathrm{~nm}$ attributing to $\mathrm{PI}$ fragment. Particularly, 3 showed distinctly fine vibrational absorption peaks at $348 \mathrm{~nm}, 366 \mathrm{~nm}$ and 386 $\mathrm{nm}$, which were attributed to $\pi-\pi^{*}$ transition of the An unit with the mole absorption coefficient of $1.26 \times 10^{4} \mathrm{~L} \mathrm{~mol}^{-1} \mathrm{~cm}^{-1}$. So it was demonstrated that An and PI units did not form stronger $\pi$ conjugation as a result of the highly twisty structure [42-44]. From $400 \mathrm{~nm}$ to $450 \mathrm{~nm}$, there was a smaller absorption band with the mole absorption coefficient of $1.89 \times 10^{3} \mathrm{~L} \mathrm{~mol}^{-1} \mathrm{~cm}^{-1}$, which might be due to the formation of charge transfer (CT) between An and PI units. The solvation effect on PL characteristic of these compounds were investigated in different solvent with ranged polarity. As shown in Figure 2f, broadened emission with no fine vibrational structure was observed in low-polarity solvents (n-hexane) of $\mathbf{3}$ in contrast with $\mathbf{1}$ and $\mathbf{2}$, which implies CT characteristic dominate the excited state of 3. As compared, the fine vibration of absorption bands about $345 \mathrm{~nm}$ of $\mathbf{2}$ were not that well-defined, which is originally owing to the $\pi-\pi^{*}$ transition of the Py unit $[21,38]$. The stronger mole absorption coefficient of nearly $3 \times 10^{4} \mathrm{~L} \mathrm{~mol}^{-1} \mathrm{~cm}^{-1}$ suggested its more conjugated length, which was favorable to realize higher PLQY. 2 showed the relatively small bathochromic shift emission peak along with the polarities increased, implying no typical intramolecular charge transfer existed.
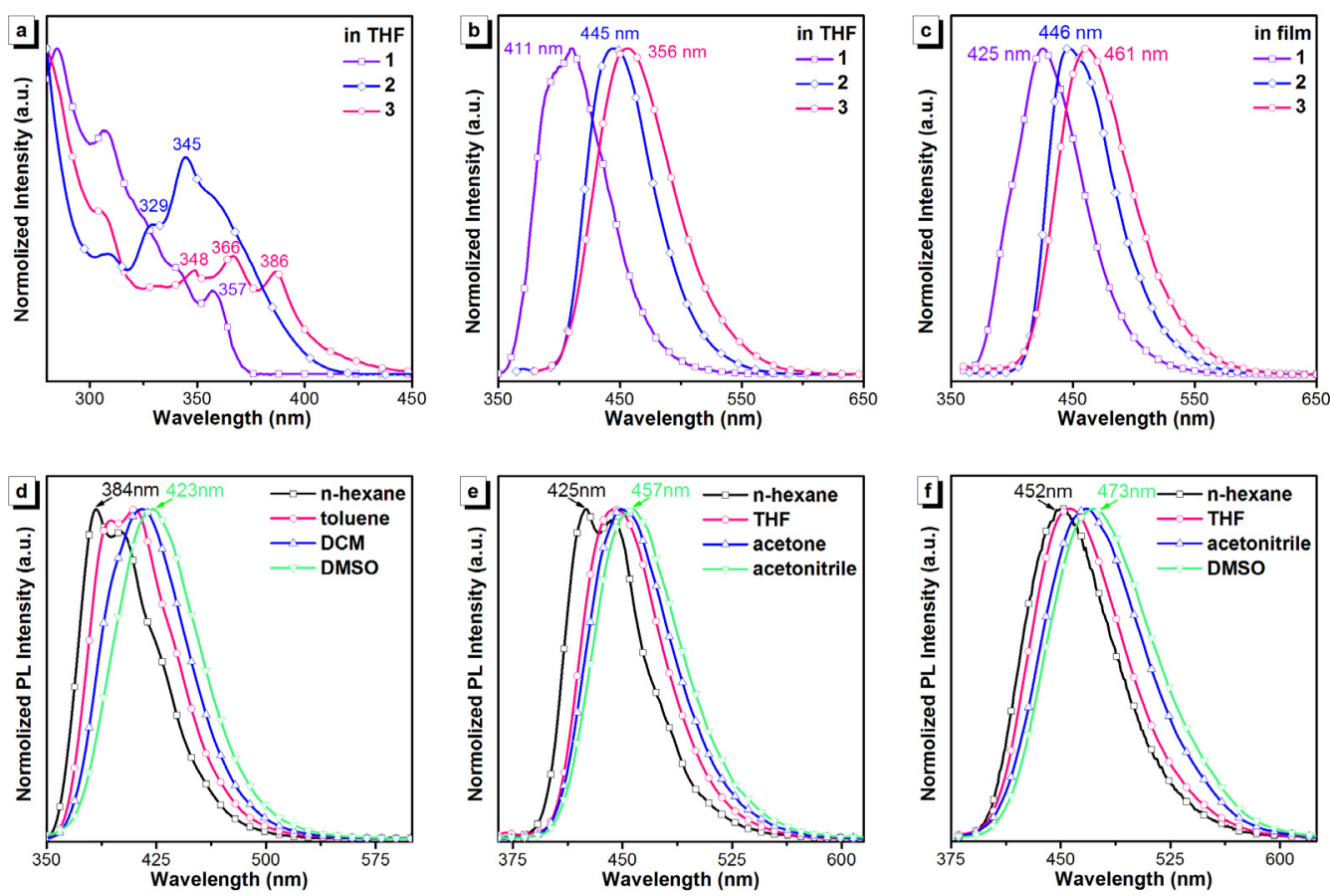

Figure 2. (a) Absorption spectra and (b) PL spectra in dilute THF (10-5 M). (c) PL spectra in neat film. (d) PL spectra of 1 in different solvents $\left(10^{-5} \mathrm{M}\right)$; (e) PL spectra of 2 in different 
solvents $\left(10^{-5} \mathrm{M}\right)$; (f) PL spectra of 3 in different solvents $\left(10^{-5} \mathrm{M}\right)$.

The fluorescent quantum yields of these compounds in dilute THF (Concentration: $10^{-5} \mathrm{~mol}$ $\mathrm{L}^{-1}$ ) measured by utilizing quinine sulphate in $1 \mathrm{~mol} \mathrm{~L}^{-1}$ sulphuric acid as a standard, determined $77 \%, 90 \%$ and $41 \%$ for 1,2 and 3 , respectively. Because of the introducing of the naphthalene and Py, the enlarged conjugation could add the route of the radiation transition. The severe CT of 3 made it relatively difficult to generate effective radiative transition [42]. Moreover, too much nonradiative decay might occur due to the torsion angle of nearly $90^{\circ}$. Further fluorescence lifetime and PLQY in solid film were measured to predict application for OLEDs fabrication. It is noticeable that no delayed lifetime component were observed among the studied molecules with prompt lifetime of less than 2ns (Figure S5). Such short lifetime and poor PLQY in various states of 3 could be speculated from a fast nonradiative decay rate [43], which validate the previous hypothesis. 1 and $\mathbf{3}$ preserve nearly identical PLQY in film. Rationally, the decreased PLQY of $57 \%$ for 2 can be tentatively assigned to the concentration quenching from intermolecular aggregation as the same as many Py derivatives [38]. Pertinent photophysical data are summarized in Table 1.

Table 1. Key Physical Properties of 1-3.

\begin{tabular}{cccccccc}
\hline Compound & $T_{\mathrm{g}} / T_{\mathrm{c}} / T_{\mathrm{m} /} T_{\mathrm{d}}\left({ }^{\circ} \mathrm{C}\right)^{\mathrm{a}}$ & $\lambda_{\mathrm{abs}}(\mathrm{nm})^{\mathrm{c}}$ & $\lambda_{\mathrm{PL}}(\mathrm{nm})^{\mathrm{d}}$ & $\mathrm{PLQY}(\%)^{\mathrm{e}}$ & $E_{\mathrm{g}}(\mathrm{eV})^{\mathrm{f}}$ & $E_{\mathrm{T}}(\mathrm{eV})^{\mathrm{g}}$ & $\mathrm{HOMO} / \mathrm{LUMO}(\mathrm{eV})^{\mathrm{h}}$ \\
\hline 1 & $99 /$ n.o.b/296/371 & $284 / 307 / 357$ & 425 & $77 / 82$ & 3.37 & 2.83 & $-5.62 /-2.21$ \\
2 & n.o./n.o./n.o./421 & $308 / 329 / 345$ & 446 & $90 / 57$ & 3.01 & 2.01 & $-5.52 /-2.52$ \\
3 & $140 / 237 / 326 / 386$ & $306 / 348 / 366 / 386$ & 461 & $41 / 34$ & 2.94 & 1.74 & $-5.62 /-2.64$ \\
\hline
\end{tabular}

a $T_{\mathrm{g}}$ : glass transition temperature; $T_{\mathrm{c}}$ : crystallization temperature; $T_{\mathrm{m}}$ : melting point; $T_{\mathrm{d}}$ : decomposition temperature (corresponding to $5 \%$ weight loss). ${ }^{b}$ n.o.=not observed. ${ }^{c}$ Absorption peaks in dilute $\mathrm{THF}\left(10^{-5} \mathrm{M}\right) .{ }^{\mathrm{d}}$ Emission peak in neat film. ${ }^{e}$ Photoluminescence quantum yield in dilute THF solvents were measured relative to quinine sulfate/ and neat film measured by integrating sphere. ${ }^{f}$ Optical gap calculated from the absorption onset in dilute THF. $g$ Triplet energy calculated from the first vibrational peak of phosphorescent spectrum. ${ }^{\mathrm{h}} \mathrm{HOMO} / \mathrm{LUMO}$ energy levels estimated by cyclic voltammetry.

To further examine their triplet excited states properties, phosphorescence emission is desired to estimate the T1 energy $\left(E_{T 1}\right)$. The steady state phosphorescent emission of 1 is recorded at $77 \mathrm{~K}$ in glassy THF, showing phosphorescent peak at $437 \mathrm{~nm}$ blended in fluorescence, corresponding to an $E_{\mathrm{T} 1}$ of $2.83 \mathrm{eV}$. However, by directly exciting $\mathbf{2}$ and $\mathbf{3}$ with proper laser flash, the triplet emission were not accessible at the same experiment condition as can be seen in Figure $3 \mathrm{~b}$ and 3c, thereby time-resolved PL was carried out to measure the delayed emission from phosphorescence. Fortunately, the delayed emission of $\mathbf{2}$ showed clearly the presence of a weak red emission centred at $617 \mathrm{~nm}(2.01 \mathrm{eV})$, whereas the 
delayed emission of 3 can only be detected by exciting at $550 \mathrm{~nm}$ laser flash using PtOEP as sensitizer [41]. The first vibrational peak of phosphorescence is $713 \mathrm{~nm}(1.74 \mathrm{eV})$ arising from the long conjugation axis of $A n[16,45]$. The estimated $E_{\mathrm{T} 1}$ indicate the lowest triplet excited states are localized on Py and An group for 2 and 3 respectively, being in accord with literatures [45-46]. Their $E_{\mathrm{S} 1}$ could also be extrapolated from steady state fluorescence emission at $77 \mathrm{~K}$ in glassy THF, demonstrating $3.13 \mathrm{eV}(396 \mathrm{~nm}), 2.79 \mathrm{eV}(444 \mathrm{~nm})$ and 2.81 $\mathrm{eV}(442 \mathrm{~nm})$ for 1,2 , and 3. According to the absorption onset, the optical gaps of these compounds were calculated to be $3.37 \mathrm{eV}, 3.01 \mathrm{eV}$ and $2.98 \mathrm{eV}$, respectively. The rational singlet and triplet energy meeting the conditions of $2 E_{\mathrm{T} 1}>E_{\mathrm{S} 1}$, make them capable of upconverting triplets into singlets through TTA.
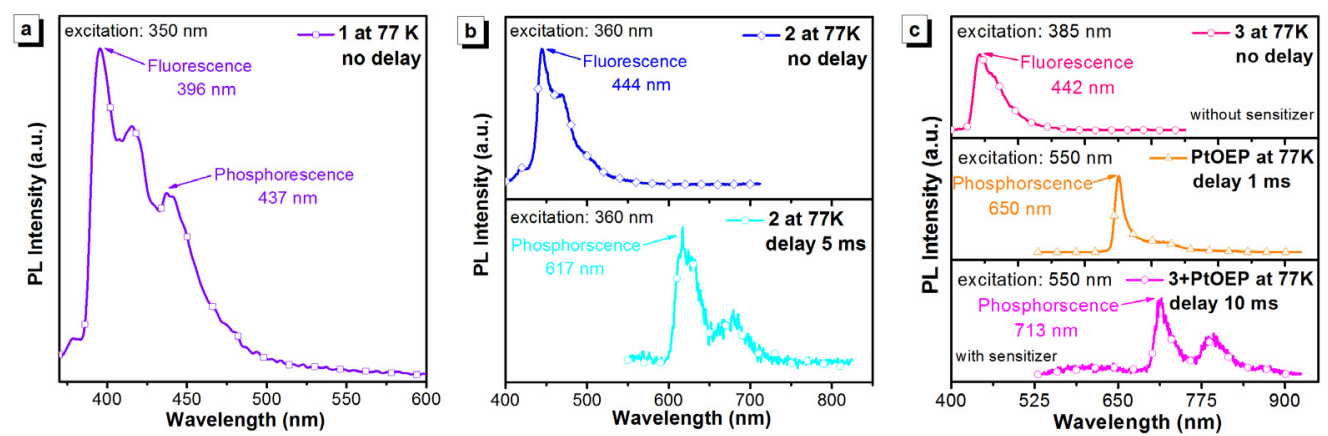

Figure 3. (a) PL spectra of 1 measured in glassy THF $\left(10^{-5} \mathrm{M}\right)$ at $77 \mathrm{~K}$. (b) PL spectra and delayed PL spectra of 2 in glassy THF $\left(10^{-5} \mathrm{M}\right)$ at $77 \mathrm{~K}$. (c) PL spectra and delayed PL spectra of 3 in glassy THF $\left(10^{-5} \mathrm{M}\right)$ at $77 \mathrm{~K}$. In the delayed PL spectra, PtOEP as the phosphorescent sensitizer was added with the same concentration with 3.

\subsection{Electroluminescence properties}

To explore their applicable potential application as blue emitter in OLEDs, vacuumdeposited nondoped devices were fabricated based with the optimized configuration of ITO/ HATCN (6 nm)/TAPC (x nm) /TCTA (y nm) /emitting layer (20 nm)/TPBi $(z \mathrm{~nm}) / \mathrm{LiF}(1.2 \mathrm{~nm}) /$ $\mathrm{Al}(120 \mathrm{~nm})$ (device 1-3), where ITO (indium tin oxides) and Al were used as the anode and cathode respectively, HATCN (hexaazatriphenylenehexacabonitrile) served as the hole injection layer, TAPC (1,1'-bis(di-4-tolyl-aminophenyl)cyclohexane) served as the hole transporting layer (HTL), TCTA (tris(4-carbazoyl-9-ylphenyl)amine) served as the exciton block layer, the emitting layer was 1 or 2 or 3, TPBi (1,3,5-tris(1-phenyl-1Hbenzimidazol-2yl)benzene) served as the electron transporting layer (ETL) and LiF served as the electron injection layer. The key performance parameters of the devices are summarized in Table 2. 
Device 1-3 showed deep blue, pure blue and sky blue stable EL spectra at various voltages (Figure S7), which were consistent with their PL counterpart in the solid state film, indicating the emission originated from the emitting layer without emission from interface exciplex.
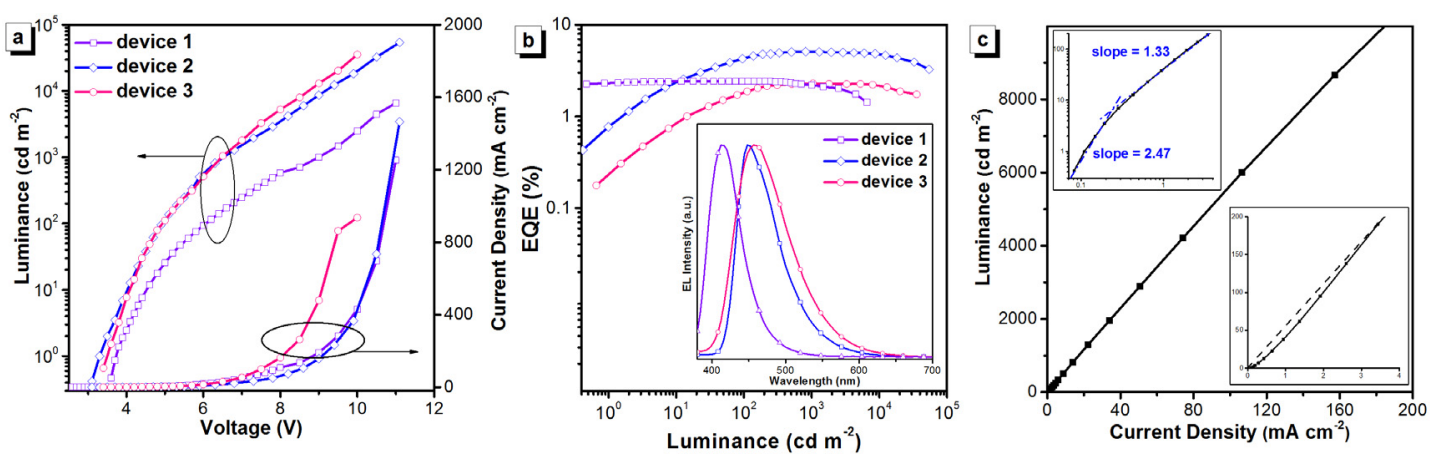

Figure 4. Characteristics of nondoped devices 1-3: (a) Current density $(J-V)$ and luminance (L-V) plots; (b) EQE-luminescence curves and the insert: EL spectra at $100 \mathrm{~cd} \mathrm{~m}^{-2}$. (c) The luminance-current density curves and the insert enlarges the low current density region of the main graph in liner and logarithmic coordinate axis respectively. Solid and broken lines are shown as guides to illustrate its nonmonoexponential relationship.

Table 2. Electroluminescent Properties of Nondoped Devices 1-3 with the structure of ITO/HATCN (6 nm)/TAPC (x nm) /TCTA (y nm) /emitting layer (20 nm)/TPBi $(z \mathrm{~nm}) / \mathrm{LiF}$ $(1.2 \mathrm{~nm}) / \mathrm{Al}(120 \mathrm{~nm})$.

\begin{tabular}{cccccccc}
\hline Device & $\begin{array}{c}\mathrm{x}, \mathrm{y}, \mathrm{z} \\
(\mathrm{nm})\end{array}$ & $\begin{array}{c}V_{\mathrm{on}} \\
(\mathrm{V})^{\mathrm{a}}\end{array}$ & $\begin{array}{c}L_{\max } \\
\left(\mathrm{cd} \mathrm{m}^{-2}\right)^{\mathrm{b}}\end{array}$ & $\begin{array}{c}\mathrm{CE}_{\max } \\
\left(\mathrm{Cd} \mathrm{A}^{-1}\right)^{\mathrm{c}}\end{array}$ & $\begin{array}{c}\mathrm{EQE} \max / 100 / 1000 / 10000 \\
(\%)^{\mathrm{d}}\end{array}$ & $\begin{array}{c}\mathrm{EL} \lambda_{\max } \\
(\mathrm{nm})^{\mathrm{e}}\end{array}$ & $\begin{array}{c}\mathrm{CIE} \\
(\mathrm{x}, \mathrm{y})^{f}\end{array}$ \\
\hline $\mathbf{1}$ & $40,10,30$ & 3.8 & 6580 & 0.513 & $2.43 / 2.41 / 2.02 /--$ & 412 & $0.160,0.035$ \\
$\mathbf{2}$ & $15,15,40$ & 3.2 & 54300 & 5.88 & $5.11 / 4.57 / 5.10 / 4.76$ & 448 & $0.154,0.141$ \\
$\mathbf{3}$ & $23,15,37$ & 3.5 & 35600 & 3.43 & $2.29 / 1.83 / 2.28 / 2.17$ & 460 & $0.164,0.185$
\end{tabular}

a Turn on voltage at the luminescence of $1 \mathrm{~cd} \mathrm{~m}^{-2} .{ }^{\mathrm{b}}$ Maximum luminescence. ${ }^{c}$ Maximum current efficiency. ${ }^{\mathrm{d}}$ External quantum efficiency of maximum/at $100 \mathrm{~cd} \mathrm{~m}^{-2} /$ at $1000 \mathrm{~cd} \mathrm{~m}^{-2} /$ at $10000 \mathrm{~cd} \mathrm{~m}^{-2}$. e Emission peak of EL at an operating voltage of $7 \mathrm{~V} .{ }^{\mathrm{f}} \mathrm{CIE}$ coordinates at an operating voltage of $7 \mathrm{~V}$.

Apparently, device 1 demonstrated a stable EQE curve with negligible efficiency roll-off resulting from the extremely balanced carriers mobility of 1 as we report previously [34]. Nevertheless, device $\mathbf{2}$ and $\mathbf{3}$ displayed distinctly roll-up efficiency curves at low current density $\left(<6 \mathrm{~mA} \mathrm{~cm}^{-2}\right)$ and nearly invariable efficiency between 6 and $100 \mathrm{~mA} \mathrm{~cm}-2$, which coincides with previous analysis in literatures about TTA [47]. From the theoretical perspectives, the amount of created triplet excitons would be linear with current density, assuming the carrier recombination efficiency is $100 \%$ in emitting layer. The triplet excitons 
concentration closely related to TTA probability would be quadratic functions of current density, leading to the accompanied TTA-related emission being approximately proportional to the square of the current density at low current density condition $[14,47]$. Furthermore, the quadratic dependence of TTA-related emission on current density would switch to linear one as the TTA probability tend to saturate at high current density regime. Although we cannot split the TTA-related delayed emission from EL luminance under the limit of test instrument to deploy analysis mathematically, the luminance curve of device 2 in Figure 4c showed distinctly nonmonoexponential relationship with current density, which signified the quadratic dependence of TTA-related emission on current density substantially. In good accordance with the theoretical discussion, there was a clear switchover to linear dependence at relatively high current density of $6 \mathrm{~mA} \mathrm{~cm}^{-2}$. On the other hand, no TTA characteristics was observed in device 1, probably because its $E_{\mathrm{T} 1}$ is too high $(2.83 \mathrm{eV})$ to fuse a double energy excited state theoretically.

Considering 2 showed great potential in nondoped device, we tentatively fabricated some doped devices with the device configurations of ITO/HATCN (6 nm)/TAPC (20 nm) /TCTA (10 $\mathrm{nm}) / \mathrm{CzSi} 2(25 \mathrm{~nm}, \mathrm{x} \% \mathrm{wt}) / \mathrm{TPBi}(40 \mathrm{~nm}) / \mathrm{LiF}(1.2 \mathrm{~nm}) / \mathrm{Al}(120 \mathrm{~nm})$, in which dopant concentrations were 10 40\% wt and $\mathrm{CzSi}$ was used as host. However, the performance of these devices were inferior to the nondoped one, and the optimal dopant concentrations was $40 \%$. Detail device performances were summarized in Table S3 and Figure S10. The deterioration of device performance might because the dispersive dopant dcreases the triplet excitons concentration resulting lower TTA probability. The larger dopant concentration demonstrated better device performance can also certify the high efficiency of device 2 derived from TTA.

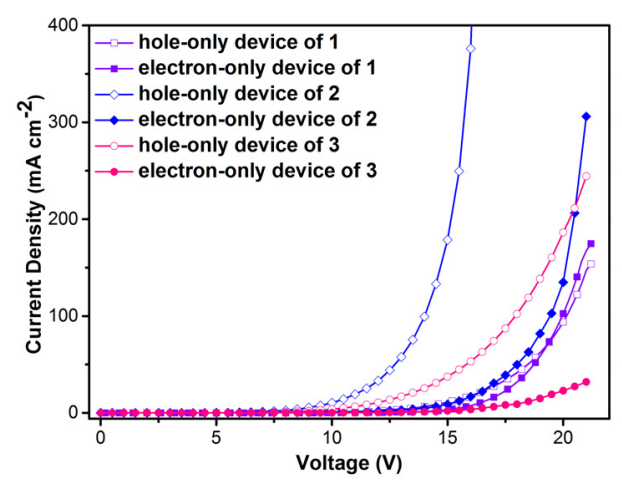

Figure 5. Single carrier devices of 1-3.

Considering that device $\mathbf{3}$ also displayed EQE and luminance curves in a very similar 
manner, there would be certain TTA contribution in EL process, but only a maximum EQE of $2.29 \%$ was received due to the poor PLQY. The severe CT property of 3 made it exhibited broadened and red-shift EL spectrum. Accordingly, the vertical structure of $\mathbf{3}$ is crucial and leads to implications for the disappointing determination of the other constituting factors. Fortunately, as can be seen in Figure 4b, an excellent performance was achieved in device $\mathbf{2}$, demonstrating the remarkable EQE of $4.57 \sim 5.11 \%$ at luminance of $100 \sim 1000 \mathrm{~cd} \mathrm{~m}^{-2}$ and a maximum luminance of $54300 \mathrm{~cd} \mathrm{~m}^{-2}$, which is responsible for its favorable PLQY and appreciable TTA contribution. In addition, the EQE could even sustain $4.76 \%$ at a significant luminance of $10000 \mathrm{~cd} \mathrm{~m}^{-2}$ with a stable pure blue emission (CIE coordinates of $(0.154$, $0.140))$.

To further investigate the correlation of triplet population depletion in EL processes, single carrier devices were fabricated with the configuration of ITO/HATCN $(6 \mathrm{~nm}) / \mathrm{NPB}(10 \mathrm{~nm}) / 1$ or 2 or $3(70 \mathrm{~nm}) /$ NPB $(20 \mathrm{~nm}) / \mathrm{Al}(120 \mathrm{~nm})$ for hole-only device and ITO/TPBi $(20 \mathrm{~nm}) / \mathbf{1}$ or 2 or $3(70 \mathrm{~nm}) / \mathrm{TPBi}(10 \mathrm{~nm}) / \mathrm{LiF}(1.2 \mathrm{~nm}) / \mathrm{Al}(120 \mathrm{~nm})$ for electron-only device. For hole-only device, NBP (N,N'-bis(naphthalen-1-yl)-N,N'-bis(phenyl)-benzidine) layer next to the Al was designed to block electron. Likewise, in the electron-only device, TPBi layer close to anode is employed to avoid hole injection [48]. As illustrated in Figure 5, the electron transporting ability of $\mathbf{3}$ was quite low probably due to the highly twisty structure, and hole one was increased compared to 1 originating from the introduction of An [10], therefore the unsatisfactory device performance might partly impute its poor and lopsided carrier transporting property. Conversely, the carriers mobility of $\mathbf{2}$ was much superior to $\mathbf{1}$ due to the introduced Py unit. However, the too strong hole transporting ability with the accompanied unbalanced carrier transporting property is detrimental to attaining perfect device performance, which could also be extrapolated from the summary of optimization of device configuration (Table S2). The performance of devices based on 2 were substantially depended on the relative thickness of HTL and ETL. Together with the too strong hole transporting property, it might be taken as an indication that the deactivation processes of serviceable excitons were mainly quenched by too much cation radicals in accumulated emitting layer, yielding triplet-state lifetimes from tens to hundreds of microseconds, which is a kind of triplet-polaron quenching (TPQ) process [49]. The decrease in redundant carrier concentrations through optimizing device configuration may be expected not only to lower operational voltage but also to enhance TTA and overall EL efficiency. 
To evaluate the TTA contribution indetail, the singlet exciton ratio could be calculated according to the following equation:

where $y$ is the carrier recombination efficiency which is supposed to be $100 \%$ only if holes and electrons are fully balanced and completely recombined to form excitons in emitting layer, $\eta_{r}$ is the singlet excitons ratio, $\eta_{\text {out }}$ is the light out-coupling efficiency (ca. $20 \% \sim 25 \%$ for blue OLEDs [50-51]), and $\Phi_{P L}$ is photoluminescence quantum efficiency, i.e., measured as $57 \%$ of 2 film. Therefore, the $\eta_{r}$ in device 2 is calculated to be $36 \sim 45 \%$. It is notably particularly that, the $y$ would be less than $100 \%$ actually because of its unbalanced carrier transporting property. Consequently, the $\eta_{r}$ should be larger than calculated value substantially. Given that the $\eta_{r}$ in exemplary fluorescent OLEDs is generally limited to $25 \%$ and such luminancecurrent density curve behavior, it cloud be safely concluded that TTA played an important role in impacting the performance of device 2.

\section{Conclusion}

In summary, two newly blue-emitting materials, $\mathbf{2}$ and $\mathbf{3}$ are successfully designed and synthesized via incorporation of pyrene and anthracene into phenanthroimidazole. The twist structure suppress the intermolecular aggregation and retain fluorescence efficiency in solid state to a certain extent. Numerous photophysical analysis prove them capable of harvesting triplet excitons through TTA in EL processes. The nondoped OLEDs of 2 demonstrates stable pure blue emission with CIE coordinates of $(0.15,0.14)$, EQE of $4.57 \% \sim 5.11 \%$ at luminance of $100 \sim 1000 \mathrm{~cd} \mathrm{~m}^{-2}, 4.76 \%$ at a luminance of $10000 \mathrm{~cd} \mathrm{~m}^{-2}$ and maximum luminance of $54300 \mathrm{~cd} \mathrm{~m}^{-2}$. Such device performance and far surpassed $25 \%$ singlet exction ratio are responsible for the appreciable TTA contribution in EL processes substantially. Our study provide the great potential of pyrene derivatives in fabricating blue OLEDs with outstanding efficiencies at high luminance, and show great promise to actualize ultra-bright WOLEDs for general-purpose lightings.

\section{Acknowledgements}

We appreciate the financial support from the National Science Foundation of China (21374038) and Jilin Provincial Science and Technology Department (20160101302JC).

\section{References}


[1] Tang C W, VanSlyke S A. Organic electroluminescent diodes[J]. Applied physics letters, 1987, 51(12): 913-915.

[2] Xiang C, Koo W, So F, et al. A systematic study on efficiency enhancements in phosphorescent green, red and blue microcavity organic light emitting devices[J]. Light: Science \& Applications, 2013, 2(6): e74..

[3] Kondakov D Y. Triplet-triplet annihilation in highly efficient fluorescent organic lightemitting diodes: current state and future outlook[J]. Philosophical Transactions of the Royal Society of London A: Mathematical, Physical and Engineering Sciences, 2015, 373(2044): 20140321.

[4] Zhang Q, Li J, Shizu K, et al. Design of efficient thermally activated delayed fluorescence materials for pure blue organic light emitting diodes[J]. Journal of the American Chemical Society, 2012, 134(36): 14706-14709.

[5] Hsieh C H, Wu F I, Fan C H, et al. Design and synthesis of iridium bis (carbene) complexes for efficient blue electrophosphorescence[J]. Chemistry-A European Journal, 2011, 17(33): 9180-9187.

[6] $\mathrm{Xu} \mathrm{H}$, Chen $\mathrm{R}$, Sun $\mathrm{Q}$, et al. Recent progress in metal-organic complexes for optoelectronic applications[J]. Chemical Society Reviews, 2014, 43(10): 3259-3302.

[7] Krotkus S, Kasemann D, Lenk S, et al. Adjustable white-light emission from a photostructured micro-OLED array[J]. Light: Science \& Applications, 2016, 5(7): e16121.

[8] Liu B Q, Wang L, Gao D Y, et al. Extremely high-efficiency and ultrasimplified hybrid white organic light-emitting diodes exploiting double multifunctional blue emitting layers[J]. Light: Science \& Applications, 2016, 5(8): e16137.

[9] Segal M, Baldo M A, Holmes R J, et al. Excitonic singlet-triplet ratios in molecular and polymeric organic materials[J]. Physical Review B, 2003, 68(7): 075211.

[10] Aydemir M, Haykır G, Battal A, et al. High efficiency OLEDs based on anthracene derivatives: The impact of electron donating and withdrawing group on the performance of OLED[J]. Organic Electronics, 2016, 30: 149-157.

[11] Luo Y J, Lu Z Y, Huang Y. Triplet fusion delayed fluorescence materials for OLEDs[J]. Chinese Chemical Letters, 2016, 27(8): 1223-1230.

[12] Mayr C, Schmidt T D, Brütting W. High-efficiency fluorescent organic light-emitting diodes enabled by triplet-triplet annihilation and horizontal emitter orientation[J]. Applied Physics Letters, 2014, 105(18): 168_1. 
[13] Ganzorig C, Fujihira M. A possible mechanism for enhanced electrofluorescence emission through triplet-triplet annihilation in organic electroluminescent devices[J]. Applied physics letters, 2002, 81(17): 3137-3139.

[14] Kondakov D Y. Characterization of triplet-triplet annihilation in organic light-emitting diodes based on anthracene derivatives[J]. Journal of Applied Physics, 2007, 102(11): 114504.

[15] Kondakov D Y, Pawlik T D, Hatwar T K, et al. Triplet annihilation exceeding spin statistical limit in highly efficient fluorescent organic light-emitting diodes[J]. Journal of Applied Physics, 2009, 106(12): 124510.

[16] Chiang C J, Kimyonok A, Etherington M K, et al. Ultrahigh Efficiency Fluorescent Single and Bi-Layer Organic Light Emitting Diodes: The Key Role of Triplet Fusion[J]. Advanced Functional Materials, 2013, 23(6): 739-746.

[17] Kido J, lizumi Y. Fabrication of highly efficient organic electroluminescent devices[J]. Applied physics letters, 1998, 73(19): 2721-2723.

[18] Chen $\mathrm{YH}$, Chou $\mathrm{H} \mathrm{H}$, Su T H, et al. Synthesis and photo-and electroluminescence properties of 3,6-disubstituted phenanthrenes: alternative host material for blue fluorophores[J]. Chemical Communications, 2011, 47(31): 8865-8867.

[19] Chou $\mathrm{P} Y$, Chou $\mathrm{H} \mathrm{H}$, Chen $\mathrm{Y} \mathrm{H}$, et al. Efficient delayed fluorescence via triplet-triplet annihilation for deep-blue electroluminescence[J]. Chemical Communications, 2014, 50(52): 6869-6871.

[20] Kim S K, Yang B, Ma Y, et al. Exceedingly efficient deep-blue electroluminescence from new anthracenes obtained using rational molecular design[J]. Journal of Materials Chemistry, 2008, 18(28): 3376-3384.

[21] Yokoyama D, Park Y, Kim B, et al. Dual efficiency enhancement by delayed fluorescence and dipole orientation in high-efficiency fluorescent organic light-emitting diodes[J]. Applied Physics Letters, 2011, 99(12): 204.

[22] Lee S B, Park K H, Joo C W, et al. Highly twisted pyrene derivatives for non-doped blue OLEDs[J]. Dyes and Pigments, 2016, 128: 19-25.

[23] Zhang D, Duan L, Zhang Y, et al. Highly efficient hybrid warm white organic light-emitting diodes using a blue thermally activated delayed fluorescence emitter: exploiting the external heavy-atom effect[J]. Light: Science \& Applications, 2015, 4(1): e232.

[24] Fröbel M, Schwab T, Kliem M, et al. Get it white: color-tunable AC/DC OLEDs[J]. Light: 
Science \& Applications, 2015, 4(2): e247.

[25] Goushi K, Yoshida K, Sato K, et al. Organic light-emitting diodes employing efficient reverse intersystem crossing for triplet-to-singlet state conversion[J]. Nature Photonics, 2012, 6(4): 253-258.

[26] Hu J Y, Pu Y J, Satoh F, et al. Bisanthracene-Based Donor-Acceptor-type LightEmitting Dopants: Highly Efficient Deep-Blue Emission in Organic Light-Emitting Devices[J]. Advanced Functional Materials, 2014, 24(14): 2064-2071.

[27] Shin M G, Kim S O, Park H T, et al. Synthesis and characterization of ortho-twisted asymmetric anthracene derivatives for blue organic light emitting diodes (OLEDs)[J]. Dyes and Pigments, 2012, 92(3): 1075-1082.

[28] Lee H W, Kim J, Kim Y S, et al. Blue emitting materials based on bispiro-type anthracene derivatives for organic light emitting diodes[J]. Dyes and Pigments, 2015, 123: 363-369.

[29] Kim B, Park Y, Lee J, et al. Synthesis and electroluminescence properties of highly efficient blue fluorescence emitters using dual core chromophores[J]. Journal of Materials Chemistry C, 2013, 1(3): 432-440.

[30] Suzuki T, Nonaka Y, Watabe T, et al. Highly efficient long-life blue fluorescent organic light-emitting diode exhibiting triplet-triplet annihilation effects enhanced by a novel holetransporting material[J]. Japanese Journal of Applied Physics, 2014, 53(5): 052102.

[31] Chen $Y H$, Lin C C, Huang M J, et al. Superior upconversion fluorescence dopants for highly efficient deep-blue electroluminescent devices[J]. Chemical Science, 2016, 7(7): 4044-4051.

[32] Cheng $Y Y$, Khoury $T$, Clady $R G C R$, et al. On the efficiency limit of triplet-triplet annihilation for photochemical upconversion[J]. Physical Chemistry Chemical Physics, 2010, 12(1): 66-71.

[33] Tang X, Shan T, Bai Q, et al. Efficient Deep Blue Electroluminescence Based on Phenanthroimidazole-Dibenzothiophene Derivatives with Different Oxidation States of Sulfur Atom[J]. Chemistry-An Asian Journal, 2017, 12(5): 552-560.

[34] Shan T, Liu Y, Tang X, et al. Highly Efficient Deep Blue Organic Light-Emitting Diodes Based on Imidazole: Significantly Enhanced Performance by Effective Energy Transfer with Negligible Efficiency Roll-off[J]. ACS Applied Materials \& Interfaces, 2016, 8(42): 28771-28779.

[35] Bai Y, Hong L, Lei T, et al. Solution-processable, single-layer, blue organic light-emitting 
diodes employing dual emitting cores of hybridized local and charge-transfer units[J]. Dyes and Pigments, 2016, 132: 94-102.

[36] Wang J, Lou X, Liu Y, et al. Controllable molecular configuration for significant improvement of blue OLEDs based on novel twisted anthracene derivatives[J]. Dyes and Pigments, 2015, 118: 137-144.

[37] Ouyang X, Li X L, Ai L, et al. Novel "hot exciton" blue fluorophores for high performance fluorescent/phosphorescent hybrid white organic light-emitting diodes with superhigh phosphorescent dopant concentration and improved efficiency roll-off[J]. ACS applied materials \& interfaces, 2015, 7(15): 7869-7877.

[38] Wu K C, Ku P J, Lin C S, et al. The photophysical properties of dipyrenylbenzenes and their application as exceedingly efficient blue emitters for electroluminescent devices[J]. Advanced Functional Materials, 2008, 18(1): 67-75.

[39] He D, Yuan Y, Liu B, et al. High performance near ultraviolet emitter based on phenanthroimidazole via substitutions at C6-and C9-positions[J]. Dyes and Pigments, 2017, 136: 347-353.

[40] Moorthy J N, Venkatakrishnan P, Natarajan P, et al. Nondoped pure-blue OLEDs based on amorphous phenylenevinylene-functionalized twisted bimesitylenes[J]. The Journal of organic chemistry, 2010, 75(8): 2599-2609.

[41] Ouyang X, Li X L, Zhang X, et al. Effective management of intramolecular charge transfer to obtain from blue to violet-blue OLEDs based on a couple of phenanthrene isomers[J]. Dyes and Pigments, 2015, 122: 264-271.

[42] Zhuang S, Shangguan R, Huang $H$, et al. Synthesis, characterization, physical properties, and blue electroluminescent device applications of phenanthroimidazole derivatives containing anthracene or pyrene moiety[J]. Dyes and Pigments, 2014, 101: 93-102.

[43] Yao L, Zhang S, Wang R, et al. Highly Efficient Near-Infrared Organic Light-Emitting Diode Based on a Butterfly-Shaped Donor-Acceptor Chromophore with Strong SolidState Fluorescence and a Large Proportion of Radiative Excitons[J]. Angewandte Chemie, 2014, 126(8): 2151-2155.

[44] Tsuboi T, Tanigawa M. Optical characteristics of PtOEP and Ir (ppy) 3 triplet-exciton materials for organic electroluminescence devices[J]. Thin Solid Films, 2003, 438: 301-307. 
[45] Zhong F, Zhao J. Phenyleneanthracene derivatives as triplet energy acceptor/emitter in red light excitable triplet-triplet-annihilation upconversion[J]. Dyes and Pigments, 2017, 136: 909-918.

[46] Chen Y H, Lin C C, Huang M J, et al. Superior upconversion fluorescence dopants for highly efficient deep-blue electroluminescent devices[J]. Chemical Science, 2016, 7(7): 4044-4051.

[47] Okumoto K, Kanno H, Hamaa Y, et al. Green fluorescent organic light-emitting device with external quantum efficiency of nearly $10 \%[\mathrm{~J}]$. Applied physics letters, 2006, 89(6): 063504

[48] Jiang W, Duan L, Qiao J, et al. Tuning of charge balance in bipolar host materials for highly efficient solution-processed phosphorescent devices[J]. Organic letters, 2011, 13(12): 3146-3149.

[49] Zhang Y, Forrest S R. Triplets contribute to both an increase and loss in fluorescent yield in organic light emitting diodes[J]. Physical review letters, 2012, 108(26): 267404.

[50] Greenham N C, Friend R H, Bradley D D C. Angular Dependence of the Emission from a Conjugated Polymer Light-Emitting Diode: Implications for efficiency calculations[J]. Advanced Materials, 1994, 6(6): 491-494.

[51] Kaji H, Suzuki H, Fukushima T, et al. Purely organic electroluminescent material realizing $100 \%$ conversion from electricity to light[J]. Nature communications, 2015, 6. 